\section{PERIODISMO Y EMPRESA PERIODÍSTICA: EL CÁDIZ DE PATROCINIO DE BIEDMA}

\author{
Pilar Vega Rodríguez
}

Universidad Complutense de Madrid pvegarod@ccinf.ucm.es
Cómo citar este artículo/Citation: Vega Rodríguez, P. (2014). "Periodismo y empresa periodística: el Cádiz de Patrocinio de Biedma". Arbor, 190 (767): a143. doi: http://dx.doi. org/10.3989/arbor.2014.767n3014

Recibido: 3 julio 2013. Aceptado: 6 abril 2014.

RESUMEN: Desde su fundación, la escritora Patrocinio de Biedma se sirvió del periódico Cádiz como portavoz del proyecto de la Federación Científico-Literaria de escritores cuyo objetivo fue la promoción de la literatura provincial y la descentralización de la vida literaria española. En los cuatro años de duración del periódico la escritora demostró extraordinarias dotes diplomáticas para, a la vez que negociaba con los tópicos de lo comúnmente aceptado para una mujer escritora, dirigir una empresa periodística desde un planteamiento profesional e insólito en una mujer.

\section{JOURNALISM AND THE JOURNALISTIC ENTERPRISE: THE CÁDIZ OF PATROCINIO DE BIEDMA}

Copyright: (c) 2014 CSIC. Este es un artículo de acceso abierto distribuido bajo los términos de la licencia Creative Commons Attribution-Non Commercial (by-nc) Spain 3.0.
ABSTRACT: Since its founding, the writer Patrocinio de Biedma used the journal Cádiz as the mouthpiece for her plans for a Literary and Scientific Federation of authors with a view to promoting provincial literature and decentralising Spanish literary life. During Cadiz's lifetime the writer showed extraordinary diplomatic skills, while playing some of the conventional roles of a woman writer, and running the newspaper in a professional way unprecedented for a woman. 
Año y medio después de su llegada a la ciudad de Cádiz, en enero de 1876, Patrocinio de Biedma puso en marcha una publicación de contenido literario, científico y filosófico que logró, muy pronto, convertirse en referente nacional por la importancia y diversidad de las firmas que aglutinaba y por su rápida difusión internacional: el Cádiz${ }^{1}$.

De Biedma tenía entonces treinta y un años. Era viuda desde los veintiocho. Había comenzado su carrera literaria escribiendo poemas en los que desahogaba el dolor por la pérdida de sus tres hijos, la había proseguido con la publicación de versos y ensayos en revistas conservadoras, y había publicado ya varias obras literarias, entre ellas las novelas Cadenas del corazón (1872) y El odio de una mujer (1875).

Con el Cádiz la carrera literaria de Patrocinio de Biedma experimentó un salto cualitativo. A lo largo de su vida, su temperamento arrojadizo la empujaría con frecuencia a empresas filantrópicas. Fue una entusiasta impulsora, por ejemplo, de la obra de la canalización del Guadalquivir para la navegación y riego entre Córdoba y Sevilla, iniciativa en la que consiguió involucrar a importantes personalidades de Andalucía (Cádiz, no 26, 20-1-1878; no 8 20-3-1879). En 1888 organizó un importante Congreso Proteccionista de la infancia, orientado a combatir la alta mortalidad infantil. Más tarde formará parte de la "Ligue des Femmes pour le désarmement international" (de la que es nombrada Vicepresidenta en 1898). Pero quizá de las obras lideradas por ella la más ambiciosa haya sido la creación del Cádiz. Con la fundación de este periódico, del que fue directora y propietaria, De Biedma se convirtió no solo en una colaboradora más de la prensa del momento sino en auténtica periodista, tal como por entonces se juzgaba a los periodistas de prestigio: profesionales que desempeñaban una función social sosteniendo una postura neutral y objetiva ante los hechos y tendencias y abordando sin miedo el debate intelectual.

Esa intención se muestra en el Cádiz desde su primer número, cuyo prospecto aprueba una perspectiva didáctica no solo para la literatura sino también para el periodismo. Si es cierto, como entonces se decía, que la responsabilidad de la muerte del libro es del periodismo, no lo es menos que también el periodismo puede actuar como el antídoto que necesita la sociedad moderna. "El periodismo mata al libro lentamente - aseguró De Biedma - y para evitarlo hay que propinar a la sociedad el remedio allí donde encuentra el mal; hay que darle la literatura en pequeñas tomas; hay que desleír el libro en el periódi- co, a fin de que se le acepte" (no 1 10-5-1877, p. 2). Porque la prensa puede también "conducir el gusto" y contribuir a la "reforma social por la instrucción artística". Consciente de esta potencialidad del periodismo De Biedma inaugura un periódico que se ocupará de ciencias, artes, literatura, salones, teatros, modas, pero también de "crónicas en que se dé cuenta de los acontecimientos más importantes del mundo en todas las esferas, hasta en la política" (ibid), siempre con amenidad y moralidad perfecta.

Pero, principalmente, con el Cádiz De Biedma trata de "romper con el centralismo que ha fijado la sede de todas estas publicaciones en Madrid" (ibid). El Cádiz veía la luz concluida la aventura federal. Pero la realidad de los hechos y la convicción de muchas opiniones políticas continuaba situando la meta intelectual del país en Madrid, donde la crítica selecta forzaba al escritor a la exigencia formal y donde sus logros alcanzaban celebridad más rápidamente. En las provincias, en cambio, los escritores sentían la obligación de celebrar los hallazgos artísticos de sus colegas, aunque fuesen primerizos, por miedo a la enemistad o resentimiento, del mismo modo que las razones de amistad o enemistad entorpecían con frecuencia la crítica y la formación del gusto. Aunque, como hacía notar De Biedma, buena parte de la literatura producida en Madrid pertenecía a las provincias, pues era obra de los diversos poetas que habían marchado a la corte en busca de oportunidades, celebridad, y compensaciones económicas. Con el Cádiz Patrocinio de Biedma se propuso crear un foro público desde el cual vincular a los escritores provinciales en un proyecto de ayuda mutua, en la promoción y desarrollo de una literatura propia. ${ }^{2}$ Para esta empresa -opinaba De Biedma - no era obstáculo el hecho de que la literatura andaluza careciese de una lengua distintiva. No era talento -tampoco- lo que faltaba a los escritores andaluces: "Lo que nos falta -decía la escritora- es energía, es voluntad, es unión para marchar de acuerdo a un punto determinado". Y lo que sobraba, poesía, "sentimiento, y falta vigor y empeño para seguir adelante" (no 3, 30-5-1877, p. 3).

Así las cosas, Patrocinio se autoimpuso el papel de vestal patriótica para impulsar y reunir a los escritores provinciales. En este llamamiento a la unidad de la literatura provincial De Biedma se sirvió de una estrategia oblicua. Partiendo de la incuestionable galantería de los andaluces se permitió apostrofar a los escritores provinciales de perezosos y susceptibles, bien segura de que la vanidad masculina no podría sentirse amenazada ni ofendida por el insulto de una 
mujer. A una mujer se le consienten empresas que hubieran sido perseguidas ferozmente de haberlas puesto en marcha un hombre: por ejemplo, esta de promover la descentralización literaria. Es decir, la escritora se sirve de su condición femenina para retar a los varones y hacerse perdonar por ese reto. $\mathrm{Y}$ su estrategia, efectivamente, tuvo éxito. Muchos de los escritores andaluces que residían en Madrid respondieron a la convocatoria de Patrocinio de Biedma en la clave prevista por ella, admirados de la tenacidad y valentía masculinas que mostraba en su proyecto. $\mathrm{Si}$ una mujer es capaz de esto, diría Santiago Arambilet, (colaborador desde Madrid) "nosotros los hombres tenemos el deber de no cejar en nuestros propósitos y consagrar todas nuestras fuerzas y todo nuestro vigor al mayor brillo y engrandecimiento de la literatura patria" (no 15, 29-9-1877, p. 114) ${ }^{3}$

El periódico cosechó un triunfo absoluto. Desde sus inicios circuló dentro y fuera de España y tuvo por suscriptores una larga lista de personalidades: de la aristocracia, de los estudios científicos y literarios y de personas inquietas aunque carentes de instrucción ${ }^{4}$. Tan solo un mes después de su nacimiento, en el n. 4, el Cádiz ya realizaba intercambio de publicación con unas 90 revistas y periódicos españoles y extranjeros, entre ellos, el Über Land und Meer de Stuttgart, el Illustrierte Zeitung de Leipzig; o el The Pictorial World de Londres (los mejores de Europa, aclara De Biedma, el 10 de agosto de 1877, no 10). Poco después, en el no 13, las publicaciones que intercambiaban con el Cádiz eran ya 145: de España, América, Francia, Bélgica, Inglaterra, Alemania, Italia y Portugal. El no 13 da noticia, también, del consejo de redacción ${ }^{5}$, integrado por importantes firmas de todo el territorio nacional y completado, posteriormente, por una larga lista de colaboradores - más de ochenta- de idéntico renombre y relevancia y de un amplísimo abanico de tendencias ideológico-políticas. La intención de Patrocinio de Biedma de abrir su periódico a todo tipo de asuntos y enfoques explica la variedad de tendencias políticas e ideológicas en redactores y colaboradores (desde los librepensadores a las autoridades eclesiásticas). "Yo he dicho - explicaba De Biedma - que en el campo neutral de la literatura admito cuanto se me ofrezca, siempre que en ello no haya ofensa para nada sagrado, ni falta para nada respetable. Por lo demás, yo no tengo enemigos; solo tengo hermanos en letras, hermanos en religión y... adictos o indiferentes!..." (no $10,10-8-1877$, p. 7). Pero semejante apertura de criterio debió producir escándalo a juzgar por la nota aclaratoria que la escritora introduce en el periódico en el $n=18$, tras reiterar la consabida apostilla de que la publicación de un texto en un periódico no implica la identificación del editor con las opiniones políticas, religiosas, filosóficas del autor. De Biedma permitirá a sus autores manifestarse libremente siempre que no conviertan sus textos "en palenque político el florido campo reservado a la literatura" (no 18, 30-10-1877, p. 8). Es esta su respuesta a una más que tácita objeción: "Queda contestado el no muy oportuno consejero anónimo, y en cuanto a dejar o no de leer el CÁDIZ, nos es completamente indiferente, $y$ puede hacerlo sin consultarnos" (ibid). Por otra parte, la neutralidad y respeto que exige la directora del Cádiz es un derecho que en primer lugar reclama para sí misma. Por eso De Biedma se pronunciará siempre como "católica y solo católica" y es significativo al respecto el apunte que dirige a un correspondiente desde las páginas de su periódico:

- ¿Con que, según declara un médium, yo he sido antes reina de Francia?...Amigo mío, no me lisonjea esto; creo que ahora soy más, porque aceptar una corona vale menos que ganarla!... Además yo soy católica y solo católica: todo lo que esté fuera del catolicismo me es indiferente!... Siento quitarle esa ilusión, pero... qué remedio!... si es la verdad! (no 10, 10-8-1877, 7).

Estas palabras no son una declaración hueca. En las páginas del Cádiz Patrocinio de Biedma llora la muerte de Pío IX, felicita al nuevo Pontífice León XIII, aborda en varios editoriales la cuestión de la indiferencia religiosa, defiende el matrimonio indisoluble, examina las relaciones entre fe, ciencia y libertad. A la vez, un análisis somero de la nómina de colaboradores del Cádiz revela que buena parte de estos escritores estaban vinculados a logias de la masonería española. Quizá esto explique también el rápido ascenso de la revista y su difusión internacional. Esta red de contactos le llegó, muy probablemente, a través de su amiga Letizia Ratazzi, y el proyecto del Cádiz podría haber comenzado a fraguarse ya en noviembre de 1875 , cuando la prensa atestigua la reunión de Patrocinio de Biedma y Madama Ratazzi en un restaurante de Madrid con varios periodistas extranjeros ${ }^{6}$. Evidentemente, las reticencias al proyecto, pese a la admiración, no faltaron. De la revista se dijo que tenía excesivo sabor cortesano y extranjero, objeción que no molestó en absoluto a Patrocinio, al contrario, fue una crítica que la llenó de satisfacción puesto que el proyecto del Cádiz había sido "crear una publicación en provincias, que estando a la altura de las de Madrid, facilitase el medio de darse a conocer a todos los jóvenes que aspirasen a ser conocidos" (no 13 10-9-1877, p. 7). 
Tres meses después del nacimiento del Cádiz, Patrocinio de Biedma volvía a la misma estrategia de oblicuidad para proponer a los escritores andaluces la creación de una Federación científico-literaria (no 16, 10-10-1877, p. 2) en la que materializar su propósito de aunar los esfuerzos de los escritores provinciales. A través de la Federación los escritores andaluces, y de modo más general todos los escritores provinciales comprometidos en la obra de la descentralización de la literatura nacional, alcanzarían el apoyo para la promoción de sus publicaciones, el asesoramiento para sus proyectos, fomentarían el debate intelectual, e incluso podrían formar un fondo de socorro económico para los casos de necesidad. De Biedma concebía la federación desde una perspectiva profesional, de ahí que propusiese una asociación reglada, costeada por las cuotas de los socios, que contase con varias publicaciones difusoras de la iniciativa y un fondo bibliográfico formado por los ejemplares de los autores miembros. De este modo, el fortalecimiento de los vínculos de unidad entre los escritores provinciales les animaría a la creación de obras en las que fuese posible reconocer las propias costumbres, lenguaje e historia, siempre desde la corrección artística y política y sin apartarse del respeto de la ley y moral del país.

La idea logrará rápidamente la adhesión de los escritores andaluces, extremeños, catalanes y en poco tiempo llegará a ser conocida fuera de nuestras fronteras. De octubre de 1877 a mayo de 1878 serán frecuentes en las páginas del Cádiz los escritos de adhesión al proyecto, las felicitaciones, las reflexiones sobre la naturaleza de la Federación y los anuncios, el más significativo, la propuesta de celebración de un Congreso Literario en Sevilla (12-5-1878) con el objeto de constituir una Junta Directiva Interina de la Federación. Dicha Junta sería la encargada de redactar el reglamento de funcionamiento de la Federación y de convocar una Asamblea General. ${ }^{7}$ En estos meses, De Biedma tratará de hacer visible la trascendencia de su proyecto y el entusiasmo que su idea despierta en los escritores, motivo por el que no perderá la oportunidad de hacer públicos los elogios a su iniciativa que llegan al periódico desde dentro o fuera de España (por ejemplo, Cuba, Brasil y Puerto Rico) copiando si es preciso de la correspondencia recibida por ella o sus amigos ${ }^{8}$. Es el caso de la carta dirigida por Henry Moore al Dr. Thebussen ( $n$ ㅇ 4, 10-6-1878, p. 25) en la que el pintor inglés dice que la Federación de Patrocinio de Biedma supone un paso de gigante en relación a las asociaciones españolas de escritores y artistas. Estas asociaciones se mantenían en España -donde aún no existía la carrera del escritor profesional-con muy pocos medios económicos y no podían ser tomadas en cuenta más que como un pasatiempo de aficionados. En cambio, atestigua Moore, la Federación de Patrocinio de Biedma se parece mucho más a las inglesas, y la propia escritora muestra con su proyecto una mentalidad tan moderna como la de las escritoras británicas del momento.

Pero tras la celebración del Congreso Literario, el 12 de mayo de 1878, la actitud de Patrocinio de Biedma respecto a su misión pública volverá a hacerse oblicua. Pasan dos meses entre la celebración del Congreso y la convocatoria de la Asamblea General. En ese ínterin desaparecen del Cádiz las abundantes reflexiones sobre la Federación. De Biedma vuelve a su estrategia de representación de un papel tópico, la musa inspiradora: "Nuestro silencio no puede creerse olvido; es más bien un sentimiento de respeto y consideración" (no 9, 30-7-1878, p. 66) -explica- hacia las personas designadas en el Congreso para formar la Junta interina que redactará el reglamento de la Federación. Entre tanto, la iniciadora de la empresa no podía hacer otra cosa "que seguir sus trabajos con amante mirada, como la madre sigue orgullosa los progresos de su hijo entregado a un sabio preceptor, para no interrumpirlos con oficiosidad inoportuna" (ibid). Pero la fórmula del Reglamento (aprobado el 6-7-1878 por una Junta en la que domina el pensamiento progresista) es sorprendente. Dicho Reglamento cataloga los socios de la Federación en socios numerarios, los escritores procedentes de Andalucía y Extremadura, con o sin título académico pero ilustrados, y socios cooperadores: personas que quieran favorecer la regeneración científico-literaria aunque carezcan de ilustración, sean escritores que provengan de otras Federaciones o de las regiones antedichas, o bien sean mujeres. Es decir, desde el principio se rechaza la profesionalización de la mujer como escritora. Es un supuesto inexistente para la Junta que va a controlar la Federación, por otra parte, únicamente formada por hombres. De Biedma, que acepta el nombramiento de Presidenta efectiva y vitalicia de la Federación, y honoraria de la Junta de Cádiz, se detiene aquí, como si entendiese que su papel concluye después de inspirar la acción. Es difícil comprender la discreción con que la escritora se retira a un segundo plano una vez conseguida la movilización proyectada.

Pero el proyecto de la Federación es un ejemplo evidente de la conciencia periodística de la escritora que se sabe líder de una empresa de opinión y acción social.

Primeramente, por la clara mentalidad empresarial de Patrocinio de Biedma, consciente de que su periódi- 
co necesita una gestión eficaz. Por esta razón será concreta y estricta en el modo de llevarlo: selecciona personalmente a sus redactores y colaboradores, instaura, muy pronto, los martes literarios, que no son otra cosa que la reunión semanal de la redacción -a la que pueden incorporarse otros invitados - se ocupa personalmente de las cuestiones administrativas, envíos, pagos, correspondencia, confirma direcciones de correo, amonesta a los periódicos que reproducen artículos del Cádiz pero no mencionan la fuente, se queja en la oficina de Correos de que los periódicos contratados no llegan a la redacción, da respuestas colectivas a sus lectores (por ejemplo, que no pueden hacerse favores personales en la redacción, por tanto, se ruega a los lectores que no sigan haciendo estas peticiones). Con una franqueza directa ejerce su papel de editora y no siente la más mínima vacilación para responder a Nicolás Díaz de Benjumea -en la sección de correspondenciaque ya le anunciará el dibujo que elige para publicar ( $\mathrm{n}$ 은 20-10-1877, p. 135) o a Jesús Pando y Valle que no puede publicar sus largas composiciones en verso ( $n$ o 15, 30-9-1877, p. 119). Por lo mismo, impone unos límites a Mr. Dubois para publicar las crónicas desde París ( $\mathrm{n}$ ㅇ 21, 30-11-1877, p. 63).

Lo cierto es que De Biedma tiene un modo curioso de dirigir la sección de Cartas ya que utiliza la sección como medio para comunicarse con sus correspondientes en lugar o además del correo ordinario, como en una especie de facebook público donde anota mensajes privados, contesta peticiones, añade apostillas, etc. ${ }^{9}$ Cito un texto:

Me he olvidado de decirle, al escribirle por el correo, que supongo no le harán olvidar las crónicas que me hace el honor de escribir para el CÁDIZ, aquel trabajo literario ofrecido (no 10, 10-8-1877, p. 79).

Esta nota, dirigida a Andrés Borrego, ahondaría la incomodidad que produjo al periodista y político la imprudencia de la escritora cuando hizo público su ofrecimiento de redactar una reseña mensual de la política para el Cádiz. La sección de crónica, se queja el escritor, necesita por principio el seudónimo para permitir la espontaneidad de juicio del periodista. Así es como lo hace la prensa inglesa. Pero con esa salvedad, Andrés Borrego entra en el oficio de "cronista-revistero", difícil como ninguno, si se trata de interpretar la escena política europea (no 8, 20-7-1877, p. 58).

En segundo lugar, si comparamos los contenidos seleccionados en los periódicos dirigidos por otras mujeres en su época, es patente que De Biedma muestra una más honda comprensión del oficio del periodista.
Revistas como La violeta, de Faustina Sáez de Melgar, publican variedad de artículos (sobre la educación, la crianza, los afectos, la moda, las virtudes femeninas) y textos literarios (poemas sentimentales, apólogos florales, folletines seriados) no solo escritos por mujeres sino también por varones doctos. Es cierto que el objeto de sus publicaciones es otro muy diferente, pero, en cualquier caso, no puede decirse que la actualidad haga aparición en estas publicaciones más allá de las ficciones realistas o los artículos didácticos. Apenas ofrecen información o secciones propiamente periodísticas ${ }^{10}$ y la crónica de la semana, cuando existe, suele ser redactada por un hombre. En La llustración de la mujer, fundada y dirigida al principio por Concepción Gimeno Flaquer, y después por Sofía Tartilán, sí encontramos crónica bibliográfica pero no de sucesos o de la semana. Lo mismo ocurre en el Ateneo Literario y artístico de señoras en cuyo prospecto llega a decir Faustina Sáez de Melgar: "No se asusten los espíritus tímidos que critican la fundación del Ateneo, ni crean que allí vamos a ocuparnos de política, ni de las graves cuestiones de Estado: las señoras congregadas en este recinto, la Asociación de ilustradas y caritativas damas, van a dar a la mujer el pan del alma; van a enseñarla sus deberes de esposa y madre, proporcionándola, al par que la utilidad el más digno y decoroso recreo" (12-1-1869, Artículo II, 1). También De Biedma escribe en el Cádiz todo tipo de textos (poemas, reseñas bibliográficas, folletines) pero su conciencia de estar al frente de una empresa periodística con una misión determinada le impulsa a reservarse siempre el editorial, desde el cual aborda temas variados (no específicamente femeninos) ${ }^{11}$ y ofrece una argumentación sólida y una voz contundente. La presencia de la actualidad en el Cádiz es notoria. La crónica de la semana se realiza con la periodicidad señalada, salvo algunas excepciones, y la firman, cuando se refiere a Madrid, Pedro Ticiano Imab (seudónimo de la propia Patrocinio de Biedma) o Brunetto (quizá Enrique Moresco, encargado en principio de la sección de bibliografía). Otras crónicas realizadas para el Cádiz son la Crónica mensual de Andrés Borrego, la Revista de Madrid firmada por Sofía Tartilán, y la Revista de Nueva York, firmada por Andrés Cassard y Cayetano del Toro. Aún cuando podría discutirse la diferencia entre crónica y revista, si comparamos, en primer lugar, las escasas crónicas de Brunetto con las de Pedro Ticiano Imab y, secundariamente, las crónicas de Imab con las revistas de Madrid de Sofía Tartilán se hace patente la clara mentalidad periodística de De Biedma. En su Revista de Nueva York Andrés Cassard se refiere a hechos como la construcción de la catedral de S. Patrick, 
el evento de un aerolito caído, la aprobación de la Bland Silver Bill, o el incendio del Excelsior, etc, n. 34, 10-4-1878). Por su parte, Cayetano del Toro, en "Los Americanos" se aplica a la comparación de los neoyorkinos y bostonianos (no 26, 20-1-1878). Pero Sofía Tartilán ${ }^{12}$ y después Salomé Núñez Topete hablan casi exclusivamente de los bailes y fiestas celebradas en Madrid, de las ferias, carreras de caballos, lecturas públicas, funciones, conciertos, de modas, o de las últimas publicaciones. En relación a ellas De Biedma se refiere a temas más comprometidos aunque adopta para referirse a estos asuntos la personalidad masculina ${ }^{13}$. Al iniciarse en su misión, el 10-1-1879 Pedro Ticiano Imab hará una declaración de principios sobre la ética del periodista comprometiéndose a dar

noticias calcadas en la verdad, exponiéndoles imparcialmente los hechos, sin que sus afecciones particulares, sus creencias políticas, ni sus compromisos de amistad, le aparten ni por un momento de este sagrado deber (no1, p. 1)

Una nueva declaración de este tipo volverá a repetirse más tarde a propósito de los rumores que corrían por el país, y de los que se hacía eco toda la prensa, sobre la boda del rey con la Archiduquesa María Cristina, y de los que los periódicos tuvieron que rectificar en varias ocasiones. Todas esas imprecisiones reflexiona Ticiano Imab "no dicen mucho en favor de la seriedad periodística"

Nada hay más irresponsable, y por lo tanto más atrevido, que el noticiero anónimo. Cualquier hombre de medianas condiciones de ilustración, moralidad y honradez, no se atrevería a afirmar en una conversación particular aquello de que no tiene seguridad, y mucho menos lo que ignora; cualquier periodista, cualquier corresponsal o reportter, afirma y sostiene bajo la irresponsabilidad que le da su posición anónima en la publicación para la cual escribe, mucho más de lo que sabe, y aun de lo que puede saber, porque llega a veces a detallar lo que no existe ( $n$ - 1, 10-9-1879, p. 1).

Esto no significa que el periodista no haya indagado lo suficiente para informar a sus lectores sino que su deseo prioritario es el de "entretener o halagar al lector, sin cuidarse de ser al día siguiente desmentido" (ibid). El público "pide siempre algo nuevo" y necesita colorear y dar interés a las informaciones que el telégrafo hace llegar de modo excesivamente escueto.

Pero la prensa tiene que respetarse a sí misma y eso lo hace "respetando las intenciones privadas, los proyectos puramente particulares". El buen periodista - había escrito Patrocinio de Biedma en el retrato del periodista Fernando García de Arboleya - no mancha jamás sus páginas con la difamación, la calumnia, o la frivolidad. No acepta jamás compensación económica del gobierno. Es siempre digno, "siempre respetuoso con quien respeto merece, siempre atento con los que le buscan y benévolo con los que le ofenden" ( $n$ ㅇ 6, 30-6-1877, p. 41); es imparcial en las apreciaciones, "comportamiento que es buena prueba de una inteligencia elevada, una rectitud moral no menos que sus sentimientos religiosos y caballerescos" (ibid). A lo largo de sus quince crónicas Ticiano Imab intentará por ello mantenerse en la pura objetividad ${ }^{14}$, en textos que coinciden, sospechosamente, con las visitas a la corte de Patrocinio. En ellos Imab hablará de multitud de asuntos: de la política de Cánovas, de los movimientos de fusión de centralistas y constitucionalistas, de las elecciones, de los obituarios de Adelardo López de Ayala, Espartero, José Ulloa y Luis Napoleón, comentará los estrenos de Echegaray y Leopoldo Cano - la novedad de las escuelas Froebel en Madrid, clamará por la plaga de incendiarios que arrasan en verano los campos. Tras la crónica de la boda de Alfonso XII vendrá la repulsa por el atentado contra la pareja real, que pone en relación con actos semejantes en Europa, y siguiendo con la política internacional se ocupará de la guerra de Afganistán.

El seudónimo sirve a Patrocinio no solo para ocuparse de la actualidad, un tema que parece masculino, sino también para ocultar su tendencia a hacerse omnímoda en el Cádiz. El plantel de colaboradores del periódico era inmenso, como ya hemos dicho. Sin embargo algunos números incluyen la firma de Patrocinio de Biedma en casi todas las secciones. Directamente, o a través de los redactores, la autora no pierde la ocasión de mencionar las publicaciones españolas y del extranjero donde se tiene en cuenta su obra literaria o filantrópica o se elogia su talento, belleza, distinción, virtudes. ${ }^{15} \mathrm{Si}$ toda esta multitud de parabienes proceden de la vanidad o responden a una estrategia indirecta de autoafirmación no es fácil determinarlo. Este punto de vanidad no consigue vencerlo De Biedma ni siquiera cuando interpreta al personaje Ticiano Imab. Por esto el cronista refiere la entrevista de Patrocinio de Biedma con el Rey con un alarde de detalles que solo podría mencionar quien hubiese participado en ella. ${ }^{16}$ Tanto es así que el revistero tendrá que salir al paso de lo que dice el periódico cubano El Progreso, de Cárdenas, recomendando las crónicas de Ticiano Imab pero matizando lo siguiente:

Publica este periódico unas magníficas revistas semanales, firmadas por un tal Pedro Ticiano Ir- 
$n a b$, escritor muy elegante y fino en las formas, así como ameno y profundo en el fondo. Hay quien dice que el tal revistero semanal es una mujer con pseudónimo de hombre pero no hay que hacer caso a quien lo asegure (año III, no 8, 20-3-1879, p. 58).

"iGracias a Dios que lo niega!...." - se apresura a contestar Ticiano Imab- "No nos sale el susto del cuerpo al pensar que se ponga en duda lo que no puede ni debe dudarse" (ibid). El desmentido llega, afirma irónicamente el cronista, no porque juzgue el talento patrimonio del cerebro masculino, sino por el pesar de ver que la sociedad se preocupa de hablar de sexos "cuando se le habla de ideas". Lo que no debe dudarse, parece sugerir el cronista, es que el talento sobrepasa la cuestión de la personalidad, el sexo o la procedencia geográfica. "'Pero olvidábamos, lectores, - concluye Ticiano Imab- que solo teníamos que defender, hoy por hoy, nuestra personalidad, que es por desgracia la que nuestro nombre indica, y decimos por desgracia porque sería preferible ser mujer distinguida a ser hombre oscuro y vulgar, del cual se dice, refiriéndose a sus escritos: "Los firma un tal Pedro » (año III, n.8, 20-3-1879, p. 58).

A fin de cuentas, parece sugerir De Biedma, raro sería que un periodista de raza, un revistero común, llegase a alcanzar la fama pública del escritor. Su destino es lograr la celebridad de otros. Y la distinguida Patrocinio de Biedma conoce bien el alcance del "cuarto poder".
1 El periplo del periódico trimensual duró desde el 10 de mayo de 1877 hasta el no 6 de 1880 (10 de junio). Se imprimía en la misma imprenta de la Crónica Gaditana, dirigida por José Rodríguez y Rodríguez, archivero jefe de la diputación de Cádiz, con el que Patrocinio de Biedma contrajo segundas nupcias en 1880. Para la descripción de las características de la revista, frecuencia, formato, columnas, grabados, secciones, precios, revistas con las que intercambiaba números, colaboradores, etc, remito a Jiménez Almagro (1984 y 1989), Contreras (1993), Perea (2004). Sobre la Federación Literaria de Patrocinio de Biedma han trabajado Cantos Casenave (1994) y Vega Rodríguez (2008)

2 Y decía la escritora: "Desearíamos que los poetas de provincias no fuesen a Madrid a buscar un nombre, sino a llevar el nombre adquirido a fuerza de trabajo y de constancia; desearíamos ver unirse en una misma aspiración a todos los literatos andaluces, formar un gran centro; crear su literatura propia, su teatro, su novela; no mendigar un puesto a la literatura castellana, sino elevar la suya de tal modo, que aquella tuviese a gloria el que se le uniera" (Cádiz, no $3,30-5-1877$, p. 18) A partir de ahora, todas las citas textuales se refieren a Cádiz salvo que se observe otra cosa.
3 La oblicuidad de la estrategia se pone de manifiesto también en la respuesta a una carta de la escritora Aurelia del Castillo desde la sección de correspondencia del periódico: "Dice Vd. que piensa de mí lo que dijeron de la Avellaneda: 'Es mucho hombre esta mujer' Yo a mi vez, recordando a Tula, y leyendo su carta, he dicho: 'Qué pródiga es la naturaleza en América; allí no hay mujer, me dije, que no tenga belleza y talento'" ( $\mathrm{n}$ $10,10-8-1877$, p. 8 ).

4 “...desde S. M. el Rey D. Alfonso XII -dice la escritora-, que nos hace el favor de leerlo, hasta el pobre artesano a quien hemos hecho servir la suscripción gratis porque nos ofrecía con pena la mitad del importe, por no ganar más". Dicha suscripción era de 25 pts. anuales (no 3, 30-5-1877, p. 1).

En el primer número (10-5-1877) figuran como colaboradores: Concepción Jimeno de Flaquer, Graciella, Ermelinda Ormaeche, madame Rattazzi, Pilar Sinúes, Faustina Sáez de Melgar, José Luis Albareda, Conde de las Almerías, Luis Alfonso, Augusto Arcimis, Eduardo Asquerino, Antonio Álvarez Jiménez, Víctor Balaguer, José Alcalá Galiano, Miguel de los Santos Álvarez, Javier de Burgos, Antonio Cánovas, Emilio Castelar, Andrés Borrego, José Castro y Serrano, Ramón de Campoamor, Rafael Campos y Vasallo, Fernando de Gabriel y Nicolás Díaz y Pérez, Doctor Thebussen, José de Echegaray, el conde de Fabraquer, Salvador María Fábregas, Francisco Flórez Arenas, Antonio Fernández Grilo, Jerónimo Flores, Francisco de Paula Flaquer, Teodoro Guerrero, Carlos Frontaura, Rafael de la Rosa, Hermenegildo Giner de los Ríos, Pedro Ibáñez Pacheco, Alejandro Harmsen, Fernando de la Serna, Fernando León y Castillo, Ramón León Mainez, José Lamarque y Novoa, Juan Miró, Lorenzo Milans del Bosch, Alfonso Moreno Espinosa, Luis Moya Jiménez, J.R de Mendoza, Julio Nombela, Ramón Navarrete, Manuel Osorio y Bernard, Abdón de Paz, Arístides Pongilioni, Francisco de Asís Pacheco, Ángel y Mauricio Rodríguez Arroquia, F.F. Steenackers (desde Lisboa), el marqués de San Miguel de la Vega, Ricardo Sepúlveda, Manuel Revilla, Antonio Romero Ortiz, Práxedes Sagasta, Antonio Trueba, Luis Vidart, Juan Tomás Salvany, Juan Vila y Blanco, Casto Vilar y García, Juan Valero y Torno, Juan Valera, Benito M. de la Vega, y Florentino Zarandona (canónigo de la catedral de Orihuela)

Se añaden paulatinamente otros colaboradores, todos ellos primeras figuras de profesiones diversas y en su mayoría varones (militares, políticos, académicos, periodistas y críticos lite- 
rarios, dramaturgos, hasta científicos), de tendencia predominante liberal y progresista aunque no falten los conservadores y los eclesiásticos. Citamos solo una muestra de ellos, desde MADRID: José M. Varela y Silvari, Carlos Coello, Manuel Palacio, Eusebio Blasco, Nicolás Díaz y Pérez, Vicente D. Bordanova, Dr. López de la Vega, Ramón Ortiz y Beneyto, Santiago Arambilet, Manuel Juan Diana, Antonio Fernández García, Manuel López Calvo, A. M. López Ramajo, Antonio García Gutiérrez, Fernando León y Castillo, Nicolás Taboada Fernández, Ramón Rodríguez Correa, Teodoro Guerrero, Sofía Tartilán, Salomé Núñez Topete, Manuel Jorreto Paniagua, Dr Fasthenrath, Núñez de Arce; desde VAlenCIA: José de Pablo y Blanco; desde Sevilla: José Ignacio S. de Urbina, el poeta D.J. Velarde, Nicolás Díaz de Benjumea; desde MÁlagA: Alejandro Sawa, Narciso Díaz de Escobar; desde JAÉN: Josefa Sevillano de Toral, Carmen Linares Martínez, José Jurado de la Parra, José Moreno Castello, Felipe de la Garza, Matías Pastor Díaz, Carmen Linares Martínez, Manuel Genaro Rentero, Pedro Manuel de Acuña, Joaquín Ruiz Jiménez, José Jurado Parra (Baeza); los escritores argentinos Rafael Obligado, Luis Tehno Pinto, y Martin Coronado.

Proporcionalmente es reducido el número de mujeres en esta lista, aunque sí célebres como Julia Asensi, Antonia Díaz Lamarque, Ángela Grassi, Emilia Calé de Quintero, Aurelia del Castillo, además de las mencionadas arriba.

5 Formada por Manuel Fernández y González, Andrés Borrego, Nicolás Díaz de Benjumea, Federico García Caballero (fallecido a finales de abril de 1878, en Sevilla) José Moreno Castelló, Ubaldo Romero Quiñones (no 13, 10-9-1877, p. 103) En el no 14 añade el periódico otros nombres a la redacción, en Cádiz: Romualdo Álvarez Espino, Servando A. de Dios, Francisco Álvarez Sánchez (farmacéutico) Francisco Flores Arenas (fallecido en octubre de 1877) Ramón León Mainez, Alfonso Moreno Espinosa, Enrique Moresco, Javier Offerrall, Vicente Rubio y Díaz, Cayetano del Toro (no 14, 20-9-1877, p. 111) Más tarde se integran José María Gómez Colón y Francisco de Dolarea (en Cádiz) Santiago Arambilet (en Madrid) y José Jurado Parra, de Baeza. En el no 3 de 30-5-1877 el Cádiz informaba de la fusión de la revista gaditana La juventud con el periódico de Patrocinio de Biedma y ponía a disposición del director y redactores de la desaparecida revista gaditana las columnas del Cádiz (p. 8).
6 “Ayer acompañaron a Mad. Ratazzi en su mesa la señora doña Patrocinio de Biedma y los Sres. Topete, Caleb Cushing (ministro de los Estados Unidos), Kins (secretario de la misma legación), Romero Ortiz, Sedaño, Hope, Raceti, Scarbourg (corresponsal de $\mathrm{Neu}$ Presse de Viena), Hougthon (corresponsal de la Independencia Belga) Hamilton (corresponsal de el Times de Londres), Bofill, Cuesta, Giovanoli y Fernández Flórez" La Época (Madrid, n.o 8.454, 21-121875, p. 3).

7 La Junta Directiva interina de la Federación literaria, nombrada en el Congreso, la integraban Juan José Bueno (presidente), Agustín M. de la Cuadra, Luis Ricardo Fors, Manuel Cano y Cueto, Rafael Molero de la Borbolla, Francisco Sánchez Arjona y Manuel Giron (secretario). La primera reunión de la Junta delegada de la Federación Literaria en Cádiz examina las adhesiones recibidas: Cayetano del Toro, A. Álvarez, B. Álvarez Espino, Francisco Dolarea, Juan de V. Pórtela, Francisco Álvarez Sánchez, J. M. Gómez Colon, José Eivas, J. Rodriguez y Rodriguez, M. López Azubialde, Enrique Gillis, E. Moresco, Carlos Kotsk, José María Rioseco, José María Mateos, Faustino Díaz, José Soler, Juan de Burgos, José Iñigo, Francisco Martínez, Adolfo Malat, Rafael Hamos (Canarias), Carlos Mantilla, Servando A. de Dios, Juan de Pol (jefe económico de la provincia), I. Gómez Plana, M. Amusátagui, Teodomiro Herrera, José de Dios, José Eivas y García, Alfonso Moreno Espinosa, F. Estudillo, Manuel Gutiérrez de la Vega, Javier de Burgo, José Franco de Teran, Enrique del Toro, José del Toro y Quartiellers, Miguel Aguado, José Calatrigo, Ramón León Mainez, Antonio Giorla y Marzan, Antonio Giorla y Marchante, José Ruiz y Ruiz, José Sartou, y Luis de Abarzuza (hermano de José de Abarzuza, presidente de la Sociedad dramática gaditana).

8 Como primeros frutos de la Federación pronto puede reseñarse la petición de anexión de Extremadura, el proyecto de fundación de las federaciones de Cuba y Puerto-Rico, con los mismos reglamentos, y bajo la presidencia honorífica de Patrocinio de Biedma (noticias en no 9, 30-7-1878, p. 9); Jesús Pando Valle comunica a la escritora el proyecto de creación de un periódico en Oviedo para apoyar los proyectos de la Federación ( $n$ ㅇ 29, 20-2-1878, p. 232) el Ateneo Barcelonés ofrece su cooperación para difundir en Cataluña el proyecto de la Federación. "La felicitación de nuestros amigos de Barcelona nos es gratí- sima, más que por la aprobación que ofrece a nuestra idea, por la esperanza nuestra que realiza, de atraer a tan noble institución a cuantos honran hoy a su patria como hombres de talento y de corazón", comenta de Biedma en la noticia (nㅇ 8, 20-7-1878, p. 63).

9 Aconseja desde la tribuna del periódico sobre el modo de realizar los pagos de las suscripciones, desea a un tío suyo una feliz excursión campestre y le anuncia que escribirá más largo por el correo postal, manifiesta sus condolencias a una amiga por su enfermedad, o a un conocido por un fallecimiento, confirma una suscripción, envía saludos a unos familiares, agradece un poema enviado, promete publicar un texto, etc.

10 En El Ángel del hogar, de Pilar Sinúes, se afirma que el periódico se destina al "hogar doméstico y la provechosa distracción de las veladas de la familia" (año II, 31-12-1865, p. 384). Faustina Sáez de Melgar dice en el prospecto de La violeta: "Nada de análisis sociales, que disecan y empequeñecen el espíritu: nada de ofrecer a sus ojos los raquíticos cuadros realistas, que buscan con afán los innovadores en nuestra época transitoria" (año I, no 1, 7-12-1862, p. 10)

11 Cuestiones de calado como "La indiferencia religiosa" (no 30, 28-2-1878, pp. 233-234); "La libertad y las libertades", editorial (no 8, 30-5-1878, p. 17); "Las revoluciones", editorial ( $n$ 은 4, 10-6-1878, pp. 25-26); "La pequeña política", sobre la educación, editorial (no 8, 20-7-1878, pp. 57-58); "La familia cristiana", artículo (no 13, 10-9-1878, p. 100): “Influencia femenina”, artículo (no 18, 30-10-1878, pp. 138-139); "La historia", artículo (no 23, 20-12-1878, pp. 178-179); "La novela", artículo (no 24, 30-12-1878, p. 187) ;“La mujer emancipada", (no 10, 10-4-1879, p. 75); "Lo que es preciso", sobre la educación de la mujer, editorial (no 21, 30-7-1879, pp. 161-162); "Los grandes problemas" ( $n$ 은 $10,10-4-1880$, pp. 73-74) y "La calceta" (no 6, 29-2-1880, pp. 41-42, respuesta a los artículos "Hacer calceta" de una suscriptora, estudiados por Cantos Casenave, 1994). El editorial se transforma en artículo cuando su espacio es sustituido por una publicación seriada como la de Romualdo Álvarez Espino, Errores en la educación. La comparación de los textos producidos por De Biedma para su periódico permite conjeturar que la escritora estaba especialmente dotada para el ensayo periodístico aunque quizá fue el género menos practicado por ella. En los editoriales y artículos 
de fondo muestra un talento analítico y una habilidad para la argumentación y la reflexión abstracta, poco común, especialmente si se tiene en cuenta su carencia de una formación reglada, que es la que puede sostener la disciplina de la lógica.

12 Sofía Tartilán, Revista de Madrid (204-1878, 20-5-1878, 20-8-1878, 30-9 1878), Revista de modas (10-11-1878, 20-12-1878, 28-2-1879). Salomé Núñez Topete ( $n$ ㅇ 34, 10-4-1878, nㅇ 35, 20-41878).

13 Interviene también en polémicas o las fomenta, como la planteada a Manuel Fernández y González (en términos de coquetería) sobre la diferencia entre "la mujer que siente y la mujer que piensa. Cuestión que imita en cierto modo el pleito en verso entablado entre Ricardo Sepúlveda y Teodoro Guerrero para discutir sobre la conveniencia o no de la soltería para el hombre, El matrimonio: pleito en verso entre T. Guerrero y R. Sepúlveda, entendiendo en él como jueces y letrados A. Arnao, A. Hurtado, A. Trueba, C. Frontaura, J.E. Hartzenbusch, N. Serra, y V.R. Aguilera. Sepúlveda solicitó a Patrocinio de Biedma actuar "como testigo sin tacha" en la segunda edición de esa disputa: "Es un honor para mí el que desee mi nombre al lado de los que tanto valen que acabo de citar, y de los no menos eminentes escritores que han sostenido el pleito ( $\mathrm{n}$ ㅇ 19, 10-11-1877, p. 7) La polémica sobre la superioridad de la mujer que siente o que piensa se inició en el Cádiz en el no 15, 29-9-1877, e intervino en ella - además de Manuel Fernández y González y la propia de Biedma (respuesta de Fernández y González y réplica de de Biedma en no 16, 20-10-1877, p. 130 y nueva respuesta del escritor granadino en $\mathrm{n}$ - 17, 30-101877 , p. 139)- la escritora Aurelia CastiIlo (no 19, 10-11-1877, pp. 146-147).

14 A las que se pueden añadir dos textos fuera del género, Las "Memorias de una mariposa", una especie de fábula poética firmada por su seudónimo (no 34 10-12-1879, pp. 266-267) y la reseña de "El pleito del matrimonio" de Ricardo Sepúlveda (no 2, el 20-1-de 1880, p. 16).

15 Se notará por ejemplo, su nombramiento como Académica honoraria preeminente en la Academia de Ciencias, Letras y Bellas Artes, de Sevilla, y en la de Ciencias y Artes de Cádiz, Académica corresponsal de la Real Academia de Bellas Artes Italiana ( $n$ o 4, 10-6-1878, p. 29), como directora honoraria de El Obrero de la Civilización, periódico que va a dar un número especial con su retrato y su biografía; la fundación en México de un centro fundado para la protección de la infancia con el nombre de la escritora, ( $n$ - 28, 10-2-1878, p. 224) la petición desde América de retra- tos, las coplas elogiosas para ella que se oyen en el carnaval de Cádiz, la apostilla, finalmente, "podemos anunciar a los que desean adquirir fotografías de la Sra. de Biedma, que han sido autorizados para su venta los Sres. Beauchy y Rodríguez" (ibid)

16 Lo mismo puede decirse de su visita a Juan Eugenio Hartzenbusch. "Era un cuadro digno de un pincel sublime el ver al ilustre anciano inclinarse sobre sus grandes libros, llenos de notas autógrafas, que les darán un valor inapreciable el día en que por desgracia nos lo arrebate la muerte, para consultar con la joven escritora la frase de interpretación dudosa, el pensamiento oscuro, sobre el cual debía su palabra hacer la luz. Con un cariño verdaderamente paternal estrechaba entre sus venerables manos las de nuestra poetisa, y oía atento su ilustrada opinión, demostrándole a cada instante su entrañable afecto y la felicidad que sentía al verla a su lado. No es de extrañar que se confundiesen las lágrimas del autor de Los amantes de Teruel y de la autora de los Recuerdos de un ángel al abrazarse, pues la familia del alma es acaso más íntima, más leal que la familia de la sangre, y los que piensan de igual modo, y de igual modo sienten, son hermanos por el corazón" ( no $11,20-4-1879$, p. 82)

\section{BIBLIOGRAFÍA}

Cantos Casenave, M. (1994). "Hacer calceta". En Canterla González, C. (coord.) De la llustración al Romanticismo: VII Encuentro: la mujer en los siglos XVIII y XIX: Cádiz, América y Europa ante la modernidad. Cádiz: Universidad de Cádiz., pp. 423-442.

Contreras, S. (1993). “Escritores giennenses en Cádiz". Boletín del Instituto de Estudios Giennenses, 150, pp. 215-236.

Jiménez Almagro, A. (1984). Estudio biográfico y crítica de Patrocinio de Biedma y La Moneda, Madrid: A. Jiménez.

Jiménez Almagro, A. (1989). Bio-bibliografía de Patrocinio de Biedma y la Mone- da:(1845-1927). Granada: Universidad de Granada.

Sáez de Melgar, F. (1862). "Prospecto". La violeta. Revista hispano-americana: literatura, ciencias, teatros y modas, 7 diciembre 1862

Sáez de Melgar, F. (1869). Ateneo artístico y literario de señoras, asociación de enseñanza universal, científica, religiosa y recreativa, 12 enero 1869.

Sinués Marco, P. (1865). "Prospecto". El Ángel del Hogar: páginas de familia: revista semanal de literatura, educación, modas, teatros, salones y toda clase de labores de inmediata y reconocida uti-

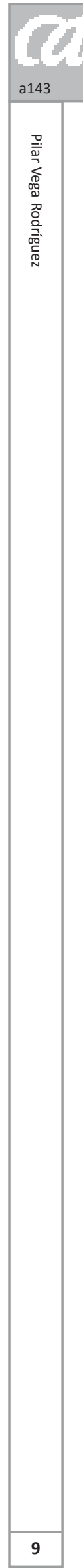

lidad: ejemplos morales, instrucción y agradable recreo para las señoritas, 31 diciembre 1865.

Perea, M.A. (2004). "La educación de la mujer en la narrativa de Patrocinio de Biedma". Boletín del Instituto de Estudios Giennenses, 187, pp. 665-792.

Vega Rodríguez, P. (2008). "Literatura nacional y literaturas regionales: el léxico de la prensa española del Romanticismo al cruce de siglo". En Romero Tobar, L. (coord.). Literatura y nación. La emergencia de las literaturas nacionales. Zaragoza: Universidad de Zaragoza, pp. 527-573. 